\title{
An educational model for preparing Christian nurses and church congregations to offer local whole-person health
} programmes

\author{
Helen Anne Wordsworth ${ }^{\mathrm{a}}$ \\ a DMin, MTh, RN, Founder and CEO of Parish Nursing Ministries and Associate Fellow at University of Durham \\ Department of Theology, UK
}

\begin{abstract}
The implications of the Tübingen declarations for congregational involvement in health provide the setting for this commentary. Using an example from the United Kingdom, where government health provision has become economically challenging and largely disease focused, the author demonstrates how it is possible to introduce the kind of education for nurses and congregations that will lead to them becoming important sources of whole-person health promotion. In this way, parish nurses and church congregations may make a distinctive contribution that will complement state and private health provision. This model has relevance across all Christian denominations. It is already being followed in 28 different countries, and with appropriate respect to culture, language and health policy, could be globally transferable.
\end{abstract}

\section{Introduction}

The article by Professor Flessa in the May 2016 edition of the Christian Journal for Global Health reviews the declarations of Tübingen in the 1960s, in the light of the subsequent development of contemporary global health provision. ${ }^{1} \quad$ Flessa suggests that even in the Christian hospitals and clinics, care has moved away from the whole person approach advocated by the Tübingen papers, and focuses largely on the cure or prevention of specific physical or mental conditions. Moreover, in low and middle income countries, the rise of good private and government provision, often much less expensive for the patient, has left the Christian health clinics and hospitals unable to compete economically. Flessa challenges the churches to review their role in global health; to decide "what criteria make them special," and to consider, "how they can find their place in the health care market." $\mathrm{He}$ suggests that if Christian influence in health and healing is to survive, the church must have something distinctive to offer. ${ }^{2}$

What then is that distinctive? The theological concept of personhood and life in the Old and New Testaments implies an understanding of health that is more than purely the absence of specific physical or mental ailments. ${ }^{3} \quad$ It encompasses community wellbeing, peace, justice, forgiveness, service with God and others,

Nov 2016. Christian Journal for Global Health, 3(2): 107-112. 
purpose, identity, the ability to give as well as receive, to use one's gifts, to be able to pray and to worship God, to choose good and to resist evil, to care for the environment, and enjoy God's creation. This is whole-person health, or "wholistic health" (the w differentiates it from the new age concept of holism), and should underlie and direct the Christian approach to health provision.

The Tübingen documents of 1964 and 1968 appear to present this concept of health. They state that:

The Christian church has a specific task in

the field of healing arising from its

understanding of its place in the whole

Christian belief about God's plan of

salvation for mankind.

The same documents then go on to suggest that the Christian ministry of healing belongs primarily to the congregation as a whole and only in that context to those who are already trained. ${ }^{2}$

In 2014, a further consultation in Germany resulted in the publication of Tübingen III. It affirms that the Christian church continues to have a unique, relevant and specific role to play in health. ${ }^{4}$

This commentary concerns one way in which the local congregation may enter in to this role, led by a specially trained and experienced community nurse. ${ }^{5}$ It will describe how Christian nurses who have no opportunity to offer wholeperson care in a secular environment can be educated to combine their nursing experience with Christian spiritual care and to work with the church, encouraging the congregation to reach out to the community in health promotional ways.

\section{Background}

Westberg, a Lutheran hospital chaplain and pioneer in the field of whole person health, saw the potential for nurses to use their skills with congregations in the 1970s. ${ }^{6}$ In 1986, Westberg pioneered the way, attaching nurses to the ministry teams of six churches in the Chicago region of the United States. Parish nursing, also known as Faith Community Nursing, is now practiced by Christian churches and organisations in 28 countries throughout the world. It was adopted first in Canada, then Australia, New Zealand, South Africa, the UK, and now South Asia, Sub-Saharan Africa, the Middle East, and South America. It combines a Judaeo-Christian understanding of health with nursing skills and a congregational involvement in health promotion. Parish nurses work by invitation with people of all ages, all faiths or no faith. They encourage healthy living, help people regain independence after surgery or acute illness, support selfmanagement of chronic conditions, and offer nonspecialist end of life care. ${ }^{7}$ They do not do invasive treatments or prescribe medications. In this way, they complement rather than compete with government and private provision. Education for this specialty has developed over the last twenty years and the core curriculum is now available to be translated and appropriately adjusted for different cultures and languages. ${ }^{8}$

Before the introduction of the National Health Service in the UK in1948 churches had been actively engaged in practical health and healing ministries. As government provision became more established, they tended to withdraw from this aspect of their ministry. This was evidenced in the changing role of deaconesses, who were the forerunners of contemporary Parish nurses; they moved from being churchbased nurses in the community to being accredited ministers in the church, and so congregations no longer played such an active role in health. ${ }^{9}$

Since then, like many "Global North" and "Global South" countries, health provision in the UK through both government and private providers has focused largely on the relief and cure of specific physical disease. But universal government provision has become economically difficult. An ageing population and the availability of new but expensive treatments for these diseases means that the time and resources

Nov 2016. Christian Journal for Global Health, 3(2): 107-112. 
left for public health programmes, mental health conditions, and spiritual care are limited. Although a patient in hospital may ask for a visit from a chaplain, and a few notable GP surgeries provide a chaplaincy service, this does not meet all of the whole person health ideals set out by the Tübingen declarations.

During the nineteen seventies, hospitals also began to lose the act of daily prayer that had been part of ward life in the nineteen fifties and sixties. Nurses now employed in the government sector are not permitted to talk about faith or pray with patients unless the patient specifically requests that and the nurse manager agrees that it may be appropriate. There have been some legal cases around this, and the result is that Christian nurses have tended to separate their nursing employment from their faith life. They are not therefore used to praying with patients. And whilst spiritual care is acknowledged as important, it is poorly understood, and there is little nursing time to focus on anything but urgent physical need. This is evidenced in nursing literature, most recently by Selby, D. et al. They studied 21 Health Care Practitioners in an acute setting, including seven nurses, and found that:

Despite spirituality being highlighted as important to care, few HCPs (Health Care Professionals) felt able to provide this, raising questions around how such care can be encouraged and developed in busy acute care settings. ${ }^{10}$

This faces the Church with the following challenge: if Christian nurses are to work with congregations and communities in promoting whole person health, how may they be educated and given permission to rediscover the ministry of prayer in appropriate ways with patients? How should they learn how to work with volunteers? And if congregations are to be more active in whole person health ministry, how are church leadership teams to be persuaded that wholeperson health demands their attention? In the UK, these questions have given rise to the progressive development of learning support for both nurses and congregations over the last twelve years, which has so far resulted in more than 85 churches of all denominations currently active in health ministry through parish nursing. ${ }^{11}$

\section{Educating Nurses}

The Westberg Institute for Faith Community Nursing, (formerly the International Parish Nurse Resource Centre) has developed some post registration/licensure education for this nursing specialty. ${ }^{12}$ For a fee, medical institutions and universities may become "Educational affiliates" and then offer the curriculum in an appropriate way for their own countries. Parish Nursing Ministries UK became an international affiliate of this programme in 2005 and were given permission to adapt the curriculum to the educational needs of nurses working in the UK context. The latest revision provides 35 hours of interactive content and is divided into the following sections:

- Spiritual care: includes understanding of your own and other faiths, and prayer.

- Professional issues: includes legal issues, ethics, record-keeping, and team-working.

- Whole-person health: includes health education, family violence, and mental health.

- Community development: includes volunteer recruitment, training, and coordination

Several institutions have devised web-based versions of the curriculum. But the context in the UK demands that it should be done with interactive small group teaching. Some nurses come to the course fearful of acknowledging that they are Christians in our multicultural state provision. They have very little understanding of the theological rationale for whole person care or of how to make connections between their faith and the nursing profession. Therefore, more content around the Hebraic concept of wholism has been added. The New Testament emphasis on the integration of spiritual healing with physical healing, spiritual care assessment, and appropriate

Nov 2016. Christian Journal for Global Health, 3(2): 107-112. 
ways of discovering whether or not a patient would like to have prayer is taught. There is also now a module on leadership. This version of the core curriculum is called the "Preparation for practice course," and is run over five days, four of which are residential. In addition, a two-day course for health care assistants is soon to be offered for those without current nursing registration, but who wish to work from their church under the leadership of a registered parish nurse. $^{13}$

Evaluation forms are collected at the end of the four-day residential, and these have been consistently positive. A portfolio of practice in the first year is also requested, which leads to the award of a badge and certificate. The portfolio includes a 1000 word summary of how the nurse sees the practice of parish nursing; a case study showing the way in which integrated care has been delivered; a theological and professional reflective piece; notes on a mentoring meeting; evidence of congregational involvement; and future plans for the ministry. This helps to evaluate the effectiveness of the course teaching, ensuring that theory turns into practice. A refresher course over two days for those who have been in practice for three years is soon to be offered.

\section{Educating Churches}

If the challenge faced in educating the nurses for this ministry is demanding, that of educating the congregation is perhaps even more difficult. The notable exception is that older members of the congregation may have grandparents that may have told of the parish nurse who went about the community working with the poor and the sick, and their approval may be more forthcoming. The leadership team, many of whom have other work pressures, face many expectations, including church management, building maintenance, legal issues, theological and pastoral concerns. They are left with little time for local mission work or community outreach, let alone health. For too long these leadership teams have seen health as the task of the state, and they may view any attempt by the church to engage with it as politically unhelpful, potentially relieving the state of its responsibilities.

But the theological and missional rationale becomes apparent when seen in the light of Missio Dei - the mission of God in the world. It becomes compelling when viewed in the context of the Biblical principles of disciples of Christ being called to reach out to their neighbours in wholistic healing activities and of integration of the spiritual and physical aspects of life. These themes should be developed in theological colleges, in leadership seminars, and in ministers' conferences. A doctoral thesis on health as a mission of the church has now been published, and a practical guide for clergy is about to become available. ${ }^{14,15}$

For a church to re-engage with health ministry requires professional support and so a not for profit organisation has been set up in the UK. Promotional and training aspects of health ministry are provided by this organization. Regional coordinators meet with the nurse and church leadership and offer a set of quality standards. When these are in place, the church's parish nursing service receives accreditation reviewed annually. The task of educating the congregation happens at both a formal and informal level.

\section{Global Developments}

This example from the UK is just one small part of a much larger movement. The Westberg Institute for Faith Community Nursing not only provides educational resources for thousands of churches and nurses across America and Canada, but also a World Forum in which international affiliates share learning and experience. This Forum is divided into regions; there is one for Asia, Africa, Australasia, South America, and Europe. There are now parish nurses or faith

Nov 2016. Christian Journal for Global Health, 3(2): 107-112. 
community nurses in each of the continents. Education for these nurses has been provided using the same basic curriculum in a contextualised way, so that, for example, in Kenya where HIV and malaria are major challenges, there are additional modules on those topics. The core curriculum is now available to be purchased and translated by applying to the Westberg Institute for Faith Community Nursing. ${ }^{16}$

In Europe, Finland still has the Lutheran "Diakonie" in its original form, with nurses attached to each church and a formal method of training that includes a theology component. Elsewhere, the "Diakonie" has become more focused on institutional care for the elderly and vulnerable. In Germany, a new and growing movement called "Vis-a-Vis" has been started by a nurse who came to the UK to train as a parish nurse, and in the Ukraine, a missionary nurse teaches the core curriculum to nurses from a variety of denominations across the country. ${ }^{17}$ The first European conference on Parish nursing is to be held in Germany in 2016.

\section{Conclusion}

Churches can offer a distinctive contribution to local community health by appointing or employing registered nurses to develop health promotional programmes that include a spiritual care component. In order to do this pioneering work, they will need educational input and professional support. The curriculum that has been developed in the US is inexpensive, and as demonstrated in this commentary is both adaptable and transferable. Its potential for use across many contexts should not be underestimated. It refocuses the church's mission on public health with the added dimension of care of the spirit. Global support and professional networking are available.

\section{References}

1. Flessa S. Christian milestones in global health: the declarations of Tübingen. Christ J Glob Heal, May 2016;3(1):11-24. http://dx.doi.org/10.15566/cjgh.v3i1.96

2. McGilvray JC. The quest for health and wholeness. Tübingen: German Institute for Medical Missions; 1981.

3. Wilkinson J. The Bible and healing; a medical and theological commentary. Edinburgh: Handsel press; 1998.

4. German Institute for Medical Missions. Symposium proceedings, Christian responses to health and development. A call to health and healing — Declaration Tübingen III.2014.

Available from:

https://www.oikoumene.org/en/resources/documen ts/other-meetings/a-call-to-health-and-healingdeclaration-tubingen-iii

5. Patterson D. The essential parish nurse. Cleveland, Ohio: Pilgrim Press, 2003.

6. Westberg GE. The parish nurse: providing a minister of health for your congregation. Westberg McNamara J, editor. Minneapolis: Augsburg Fortress, 1990.

7. Wordsworth H, Moore R, Woodhouse D. Parish nursing: a unique resource for community and district nurses. Brit J Community Nurs. 2016 Feb $1 ; 21(2)$. http://dx.doi.org/10.12968/bjen.2016.21.2.66

8. Westberg Institute for Faith Community Nursing. Foundations of Faith Community Nursing Curriculum. [2014 revision]

9. Wordsworth H. Rediscovering a ministry of health; parish nursing as a mission of the local church. Oregon: Wipf and Stock, 2015.

10. Selby D, Seccaraccia D, Huth J, Kurrpa K, Fitch,M.. A qualitative analysis of a healthcare professional's understanding and approach to management of spiritual distress in an acute care setting. J Palliat Med. Oct 2016. [ahead of print] http://dx.doi.org/10.1089/jpm.2016.0135

11. Parish Nursing Ministries UK. Available from: www.parishnursing.org.uk

12. The Westberg Institute for Faith Community Nursing, Church Health Centre, Memphis, TN. Available from: www.churchhealthcenter.org/westberg-institute 
13. Parish Nursing Ministries UK and the Westberg Institute for Faith Community Nursing. Preparation for practice workbook. 2016.

14. Wordsworth H. Rediscovering a ministry of health; parish nursing as a mission of the local church. Oregon: Wipf and Stock, .

15. Wordsworth H. Nursing and the mission of the church. Oxford: Grovebooks, 2016.

16. The Westberg Institute for Faith Community Nursing, Church Health Centre, Memphis, TN.
Available from:

www.churchhealthcenter.org/westberg-institute

17. Wordsworth H. Health ministry through local faith communities: a European perspective. Community Practitioner. 2014 Jan 1;87(1):24-8. Available from:

http://www.ncbi.nlm.nih.gov/pubmed/24597058

\section{Peer Reviewed}

Competing Interests: None declared.

Correspondence: Rev. Dr. Helen Anne Wordsworth, Parish Nursing Ministries UK. rev.h@rhwordsworth.plus.com

Cite this article as: Wordsworth HA. An educational model for preparing Christian nurses and church congregations to offer local whole-person health programmes. Christian Journal for Global Health (Nov 2016), 3(2):107-112.

C Wordsworth HA. This is an open-access article distributed under the terms of the Creative Commons Attribution License, which permits unrestricted use, distribution, and reproduction in any medium, provided the original author and source are properly cited. To view a copy of the license, visit http://creativecommons.org/licenses/by/4.0/

\section{www.cjgh.org}

Nov 2016. Christian Journal for Global Health, 3(2): 107-112. 